Table 3 Operative findings

\begin{tabular}{|c|c|c|c|c|}
\hline & \multicolumn{4}{|c|}{ Patient no. } \\
\hline & 1 & 2 & 3 & 4 \\
\hline $\begin{array}{l}\text { Parietal } \\
\text { pleural } \\
\text { thickening }\end{array}$ & Diffuse & Diffuse & Diffuse & $\begin{array}{l}\text { Multiple } \\
\text { large } \\
\text { plaques }\end{array}$ \\
\hline $\begin{array}{l}\text { Thickness of } \\
\text { parietal pleura (mm) }\end{array}$ & 7 & 5 & 6 & 8 \\
\hline $\begin{array}{l}\text { Visceral pleural } \\
\text { thickening }\end{array}$ & No & No & Yes & No \\
\hline $\begin{array}{l}\text { Adhesions between } \\
\text { visceral and parietal pleura }\end{array}$ & Yes & Yes & No & Yes \\
\hline
\end{tabular}

to benign asbestos-related pleural disease are similar to those previously reported. ${ }^{2-4}$ This condition needs to be distinguished from the more common self-limited episodes of pleural pain which can be associated with benign asbestos-related pleural effusions. ${ }^{3}$ In the series reported by Robinson and Musk ${ }^{3}$ pain lasted for an average of 10 weeks (range 2-26 weeks).

Several features supported an organic basis for our patients' pain. Firstly, pleural rubs in asbestos pleural disease are uncommon ${ }^{5}$ yet they were present in all patients on most reviews. Secondly, increased erythrocyte sedimentation rate and fever were noted. Thirdly, chest radiographs showed progressive changes. Lastly, thoracic nerve blocking procedures and thoracic epidural blocks relieved the pain.

Pleurectomy is therefore unlikely to be helpful for persistent pain due to benign asbestosrelated pleural disease where there is a significant neuralgic component. However, patients without this component who have pleuritic pain which is chronic, debilitating, and not responding to conventional analgesia may respond to the procedure.

1 Stuart G, Cramond T. The role of cervical cordotomy for pain of nonmalignant origin. Med $\mathcal{F}$ Aust 1993;158:667-70. 2 Miller A. Chronic pleuritic pain in four patients with asbestos induced pleurl fibrosic Br $\mathcal{F}$ Ind Med 1990;47:147-53.

Robinson BWS, Musk AW. Benign asbestos pleural effusions: diagnosis and course. Thorax 1981;36:896-900.

4 Hillerdal G. Non-malignant asbestos pleural disease. Thorax 1981;36:669-75.

5 Britton MG. Asbestos pleural disease. Br $\mathcal{F}$ Dis Chest 1982; 76:1-10.

6 Bond MR, Pilowsky I. The subjective assessment of pain and its relationship to administration of analgesics in patients with advanced cancer. $\mathcal{F}$ Psychosomat Res 1966;10:203-8.

\section{Pulmonary vasorelaxant activity of atrial natriuretic peptide and brain natriuretic peptide in humans}

\author{
Robert I Cargill, Brian J Lipworth
}

three study days, MPAP at $\mathbf{T}_{60}$ was lower when ANP $(18 \cdot 3(2 \cdot 0) \mathrm{mm} \mathrm{Hg})$ and BNP $(16.1(1.5) \mathrm{mm} \mathrm{Hg})$ were given concomitantly compared with placebo $(21 \cdot 8$ (1.6) $\mathrm{mm} \mathrm{Hg}$.

Conclusions - These findings indicate that both ANP and BNP exhibit pulmonary vasorelaxant activity in humans in terms of antagonism of the pulmonary pressor effects of angiotensin II. This would support the hypothesis that ANP and BNP act as circulating counter-regulatory hormones in states of pathological pulmonary vasoconstriction.

(Thorax 1995;50:183-185)

Keywords: natriuretic peptides, pulmonary circulation, angiotensin II.

Although the systemic haemodynamic effects of atrial natriuretic peptide (ANP) and brain natriuretic peptide (BNP) in humans are well documented, ${ }^{12}$ relatively little is known regarding their effects in the human pulmonary vascular bed. Both ANP and BNP have been shown to exhibit in vitro pulmonary vaso- 
relaxant activity in rats, ${ }^{3}$ and ANP infusion can reduce pulmonary vascular resistance in patients with cor pulmonale. ${ }^{4}$ In addition, the interplay between the natriuretic peptide system and the renin-angiotensin system which is important in terms of hormonal and systemic pressor effects ${ }^{5}$ has not been studied in the human pulmonary circulation.

We have therefore studied the effects of ANP and BNP on pulmonary vascular tone in humans and their interaction with angiotensin II in the pulmonary circulation.

\section{Methods}

SUBJECTS

Eight normal male volunteers of mean (SE) age $29.2(2.8)$ years were studied on three occasions. Clinical history and examination, biochemical and haematological screening, 12 lead electrocardiogram and echocardiogram were all normal, and informed consent for the study protocol previously approved by the Tayside Committee for Medical Ethics was obtained.

\section{STUDY PROTOCOL}

On each study day intravenous cannulae for peptide infusion were inserted and subjects remained supine for the remainder of the study. After resting to reach steady state baseline haemodynamics $\left(\mathrm{T}_{0}\right)$ a 60 minute infusion of either human ANP (10 pmol/kg/min), human BNP $(10 \mathrm{pmol} / \mathrm{kg} / \mathrm{min}$ ), or placebo ( $5 \%$ dextrose) was commenced. After 30 minutes $\left(\mathrm{T}_{30}\right)$ a concomitant infusion of human angiotensin II $(6 \mathrm{ng} / \mathrm{kg} / \mathrm{min})$ was started and both infusions continued for a further 30 minutes $\left(T_{60}\right)$. Haemodynamic parameters were measured just before commencing each infusion $\left(T_{0}\right.$ and $\left.T_{30}\right)$ and at the end of the total infusion period $\left(T_{60}\right)$.

MEASUREMENTS

Mean arterial blood pressure (MAP) was measured by a semi-automatic sphygmomanometer. All other haemodynamic measurements were made non-invasively by pulsed wave Doppler echocardiography. Cardiac output (CO) was measured from aortic blood flow as previously described. ${ }^{6}$ Mean pulmonary artery pressure (MPAP) was calculated from measurement of pulmonary acceleration time as described by Dabestani et al. ${ }^{7}$ Total pulmonary vascular resistance (PVR) was calculated as (MPAP/ CO) $\times 80$ dyne.s. $\mathrm{cm}^{-5}$. We have previously shown these methods to be highly reproducible with intraindividual variability (as CV\%) for measurement of pulmonary acceleration time to be $1 \cdot 7 \%$ and for aortic stroke distance $1 \cdot 2 \%$.

\section{DATA ANALYSIS}

A Statgraphics (STSC Software Publishing Group, Maryland, USA) computer software package was used to analyse the data with comparisons made by multifactorial analysis of variance and, where significant, Duncan's multiple range testing with $\mathrm{p}<0.05$ considered

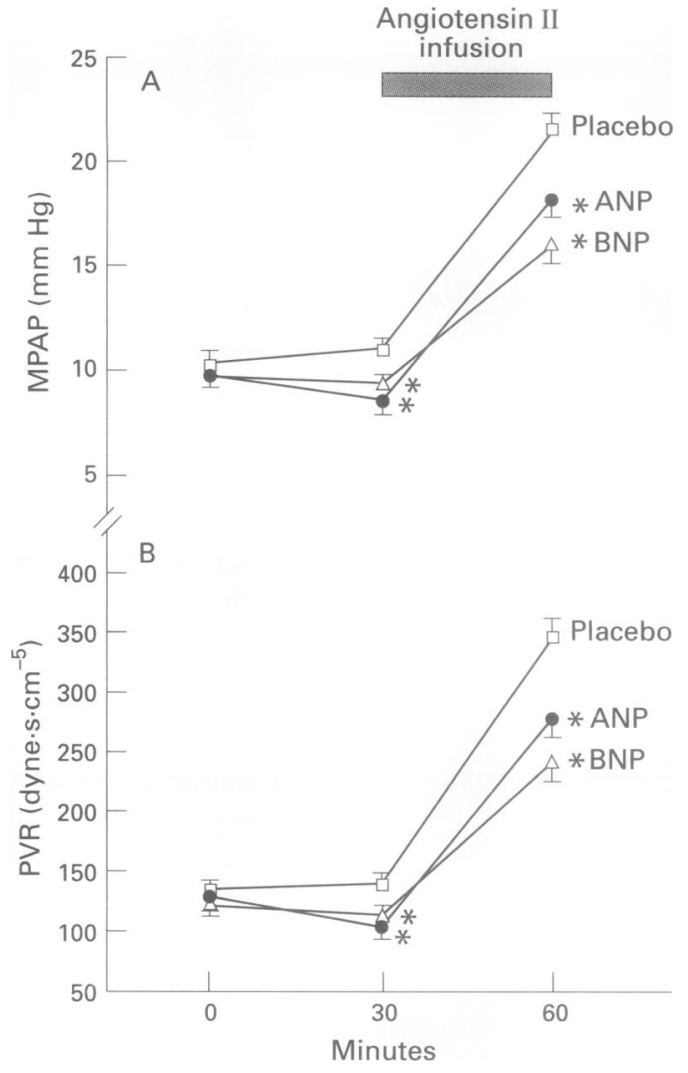

Levels of $(A)$ mean pulmonary arterial pressure (MPAP) and $(B)$ total pulmonary vascular resistance (PVR) at baseline $\left(T_{0}\right)$, after 30 minutes $\left(T_{30}\right)$ of placebo, $A N P$, or $B N P$, and following 30 minutes of concomitant angiotensin II infusion ( $\left.T_{60}\right)$. Values are means (SE). Asterisks indicate values significantly different from placebo.

significant. Values are expressed in the text as mean (SE).

\section{Results}

PULMONARY HAEMODYNAMICS

MPAP and PVR were similar at $\mathrm{T}_{0}$ on all three study days. At $\mathrm{T}_{30}$ MPAP was significantly lower following infusion of ANP and BNP than with placebo (figure). PVR at $T_{30}$ was also significantly lower after ANP and BNP infusion than after placebo (figure). Angiotensin II had significant pulmonary pressor effects although MPAP at $T_{60}$ was significantly lower when ANP or BNP were infused compared with placebo (figure). Similarly, PVR at $\mathrm{T}_{60}$ was significantly lower when ANP or BNP were given concomitantly compared with placebo (figure).

To obviate the effects of different baseline values at $T_{30}$ we calculated the change in MPAP induced by angiotensin II between $T_{30}$ and $\mathrm{T}_{60}$. The $\triangle \mathrm{MPAP}$ response was significantly attenuated by BNP $(6.9(1.0) \mathrm{mm} \mathrm{Hg})$ but not by ANP $(9.8(1.6) \mathrm{mm} \mathrm{Hg})$ compared with placebo $(10.8(1 \cdot 1) \mathrm{mm} \mathrm{Hg})$. Similarly, $\triangle \mathrm{PVR}$ was significantly attenuated by BNP (125 (22) dyne.s.cm ${ }^{-5}$ ) in comparison with ANP (177 (22) dyne.s. $\mathrm{cm}^{-5}$ ) or placebo (208 (19) dyne.s. $\mathrm{cm}^{-5}$ ).

\section{SYSTEMIC HAEMODYNAMICS}

There were no significant changes in MAP or $\mathrm{CO}$ in response to ANP or BNP infusion 
Mean (SE) systemic haemodynamic responses

\begin{tabular}{llll}
\hline & $T_{0}$ & $T_{30}$ & $T_{60}$ \\
\hline Placebo & & & \\
MAP & $88.4(2.9)$ & $87.9(1.7)$ & $116.9(3.4)^{*}$ \\
CO & $6.30(0.19)$ & $6.57(0.31)$ & $5.06(0.19)^{*}$ \\
ANP & & & \\
MAP & $90.4(2.1)$ & $86.1(2.9)$ & $107 \cdot 1(2.6)^{*} \dagger$ \\
CO & $6.41(0.19)$ & $6.92(0.40)$ & $5.25(0.19)^{*}$ \\
BNP & & & \\
MAP & $86.6(2.3)$ & $83.9(2.5)$ & $104.0(3.1)^{*} \dagger$ \\
CO & $6.57(0.38)$ & $6.73(0.38)$ & $5.28(0.34)^{*}$ \\
\hline
\end{tabular}

$\mathrm{MAP}=$ mean arterial pressure $(\mathrm{mm} \mathrm{Hg}) ; \mathrm{CO}=$ cardiac outpu $(1 / \mathrm{min}) ; \mathrm{ANP}, \mathrm{BNP}=\mathrm{atrial}$ and brain natriuretic peptides.

* Significant differences between $T_{60}$ and $T_{30} / T_{0}$.

† Significant differences compared with placebo.

(table). In response to angiotensin II CO was reduced equally on all three study days and, whilst MAP increased, levels at $\mathrm{T}_{60}$ were significantly lower during ANP or BNP infusion compared with placebo (table).

\section{Discussion}

This study demonstrates for the first time that both ANP and BNP possess in vivo pulmonary vasorelaxant activity in humans. These effects, in lowering basal pulmonary vascular tone (at $T_{30}$ ), are perhaps less important than the finding that ANP and BNP attenuated the pulmonary pressor effects of angiotensin II (at $\mathrm{T}_{60}$ ). However, since MPAP was decreased by both ANP and BNP, a more representative measure of their antagonism of angiotensin II responses might be to compare changes between $T_{30}$ and $T_{60}$ which showed that BNP, but not ANP, significantly reduced the MPAP delta response to angiotensin II. ANP and BNP may therefore play an important part as counter-regulatory hormones in states where there is pathological pulmonary vasoconstriction, particularly where there is associated activation of the renin-angiotensin system.

The exact role of angiotensin II in the pathophysiology of pulmonary hypertension and cor pulmonale is still unclear, although two findings would indicate that it has a key role in this process. Firstly, there is evidence from animal studies that angiotensin II can modulate the pulmonary vasoconstrictor response to hypoxia. ${ }^{8}$ Secondly, we have previously shown that the human pulmonary vascular bed is more sensitive than the systemic vasculature to the pressor effects of angiotensin II. ${ }^{9}$ Thus, the interaction of the natriuretic peptides and angiotensin II in the pulmonary circulation may be more marked than previously studied systemic haemodynamic effects.

Echo Doppler measurements of pulmonary haemodynamic changes in normal individuals are reproducible, ${ }^{6}$ accurate, ${ }^{7}$ and easily applied. Calculation of PVR does, however, exclude changes in pulmonary capillary wedge pressure and thus we may have overestimated the effects of angiotensin II on pulmonary vascular tone. It has, however, been shown that, for a $10 \mathrm{~mm} \mathrm{Hg}$ increase in MAP induced by angiotensin II, the associated increase in pulmonary capillary wedge pressure is only $1.7 \mathrm{~mm} \mathrm{Hg} .{ }^{10}$ Thus, in this study the magnitude of the MPAP response to angiotensin II $(10.8 \mathrm{~mm} \mathrm{Hg})$ would be greater than any calculated change in pulmonary capillary wedge pressure $(4.9 \mathrm{~mm} \mathrm{Hg})$.

The finding that ANP and BNP have pulmonary vasorelaxant activity and are antagonists of angiotensin II raises some therapeutic possibilities, perhaps in patients with cor pulmonale where the reninangiotensin system is activated. ${ }^{11}$ Increasing endogenous levels of ANP and BNP by endopeptidase $24 \cdot 11$ inhibitors may have pulmonary haemodynamic benefits or, alternatively, may suppress overactivity of the renin-angiotensin system by ACE inhibition. This latter strategy has produced conflicting results ${ }^{1213}$ but, as was the case in congestive heart failure, the true benefit may not be apparent until chronic dosing studies are evaluated.

This research programme was supported by a grant from the Scottish Hospital Endowments Research Trust.

1 Cody RJ, Atlas SA, Laragh JH, Kubo SH, Covit AB, Ryman $\mathrm{KS}$, et al. Atrial natriuretic factor in normal subjects and heart failure patients. $\mathcal{F}$ Clin Invest 1986;76:1362-74.

2 Yoshimura $M$, Yasue $H$, Morita E, Sakaino N, Jougasaki $M$, Korose $M$, et al. Haemodynamic, renal, and hormonal responses to brain natriuretic peptide infusion in patients

with congestive heart failure. Circulation 1991;84:1581-8. thao L, Hughes JM, Winter RJ. Effects of natriuretic peptides and neutral endopeptidase $24 \cdot 11$ inhibition in isol-
ated perfused rat lung. Am Rev Respir Dis 1992;146: ated perfused

4 Adnot $S$, Andrivet $P$, Chabrier PE, Piquet J, Blas $P$, Braquet $\mathrm{P}$, et al. Atrial natriuretic factor in chronic obstructive lung disease with pulmonary hypertension. F Clin Invest 1989 83:986-93.

5 Anderson JV, Struthers AD, Payne NN, Slater JDH, Bloom SR. Atrial natriuretic peptide inhibits the aldosterone response to angiotensin II in man. Clin Sci 1986;70 507-12.

6 Lipworth BJ, Dagg KD. Comparative effects of angiotensin II on Doppler parameters of left and right heart systolic and diastolic blood flow. Br $\mathcal{F}$ Clin Pharmacol 1994;37: and diasto.

7 Dabestani A, Mahan G, Gardin JM, Takenaka K, Burn C, Allfie A, et al. Evaluation of pulmonary artery pressure and resistance by pulsed Doppler echocardiography. $\mathrm{Am}$ f Cardiol 1987;59:662-8

8 Alexander JM, Nyby MD, Jasberg KA. Effect of angiotensin on hypoxic pulmonary vasoconstriction in isolated dog lung. $\mathcal{F}$ Appl Physiol 1976;41:84-8.

9 Lipworth BJ, Dagg KD. Vasoconstrictor effects of angiotensin II on the pulmonary vascular bed. Chest 1994 105:1360-4.

10 Segel N, Harris P, Bishop JM. The effects of synthetic hypertensin on the systemic and pulmonary circulations in man. Clin Sci 1960;20:49-61.

11 Lang CC, Coutie WJ, Struthers AD, Dhillon DP, Winter JH, Lipworth BJ. Elevated levels of brain natriuretic peptide in acute hypoxaemic chronic obstructive pulmonary disease. Clin Sci 1992;83:529-33.

12 Patakas D, Georgopoulos D, Rodini H, Chirstaki P. Effects of captopril in patients with chronic obstructive pulmonary disease and secondary pulmonary hypertension. Postgrad Med F 1988;64:193-5.

13 Bertoli L, Cicero SL, Busnardo I, Rizzato G, Montanari G. Effects of captopril on haemodynamics and blood gases in chronic obstructive lung disease with pulmonary hypertension. Respiration 1986;49:251-6. 